2020-09

\title{
A global approach to mapping the environmental risk of commercial harbours on aquatic systems
}

\section{Valdor, P}

http://hdl.handle.net/10026.1/15712

\author{
10.1016/j.marpol.2020.104051 \\ Marine Policy \\ Elsevier
}

All content in PEARL is protected by copyright law. Author manuscripts are made available in accordance with publisher policies. Please cite only the published version using the details provided on the item record or document. In the absence of an open licence (e.g. Creative Commons), permissions for further reuse of content should be sought from the publisher or author. 


\title{
A global approach to mapping the environmental risk of commercial harbours on aquatic systems
}

\author{
Paloma F. Valdora, Aina G. Gómez ${ }^{\mathrm{a}, \mathrm{m}}$, Peter Steinberg ${ }^{\mathrm{b}, \mathrm{c}}$, Edwina Tanner ${ }^{\mathrm{b}}$, Antony M. \\ Knights $^{d}$, Rochelle D. Seitz ${ }^{\mathrm{e}}$, Laura Airoldif, Louise B. Firth ${ }^{\mathrm{d}}$, Christos Arvanitidis \\ Massimo Pontif, Eva Chatzinikolaoug, Paul R. Brooks ${ }^{h}$ Tasman P. Crowe ${ }^{h}$, Alison \\ Smithe, Gonzalo Méndezi, Aida Ovejero', Abilio Soares-Gomesj, John A. Burtk, Catriona \\ MacLeod', José A. Juanes ${ }^{a, *}$
}

a Environmental Hydraulics Institute, Universidad de Cantabria - Avda. Isabel Torres, 15, Parque Científico y Tecnológico de Cantabria, 39011, Santander, Spain, T:+34.942.20.16.16, palomavaldor@gmail.com, aina.gomez@unican.es, juanesj@unican.es

b Sydney Institute of Marine Science, 19 Chowder Bay Rd, Mosman NSW 2088, Australia. p.steinberg@unsw.edu.au, Edwina.Tanner@sims.org.au

c School of BEES, University of New South Wales Sydney, NSW 20152, Australia, p.steinberg@unsw.edu.au

d School of Biological and Marine Sciences, University of Plymouth, Plymouth, U.K., louise.firth@plymouth.ac.uk, antony.knights@plymouth.ac.uk

e Virginia Institute of Marine Science, William \& Mary, Virginia, U.S.A., seitz@vims.edu, asmith@vims.edu

${ }^{f}$ Department of Biological, Geological and Environmental Sciences and Interdepartmental Research Centre for Environmental Sciences, UO CoNISMa, University of Bologna, Via S. Alberto 163, 48123, Ravenna, Italy, laura.airoldi@unibo.it; massimo.ponti@unibo.it

9 Institute of Marine Biology, Biotechnology and Aquaculture Hellenic Centre for Marine Research, Attiki,Greece, arvanitidis@hcmr.gr, evachatz@hcmr.gr

${ }^{h}$ UCD Earth Institute and School of Biology and Environmental Science, University College

Dublin, Dublin, Ireland, paul.brooks@ucd.ie; tasman.crowe@ucd.ie

i UNESCO Chair in Sustainable Coastal Zone Management, University of Vigo, Vigo, Spain, mendez@uvigo.es, aovejero@uvigo.es

j Sediment Ecology Laboratory, Marine Biology Department, Federal Fluminense University, Rio de Janeiro, Brazil, abiliosg@id.uff.br.

${ }^{k}$ Center for Genomics and Systems Biology, New York University Abu Dhabi, Abu Dhabi, United Arab Emirates, john.burt@nyu.edu.

I Institute for Marine and Antarctic Studies (IMAS), University of Tasmania, Australia, catriona.macleod@utas.edu.au

m Balearic Islands Coastal Observing and Forecasting System (SOCIB), Parc Bit, Naorte, Bloc A $2^{\circ}$ 3p, 07121 Palma de Mallorca, Spain

*Corresponding author E-mail addresses: juanesj@unican.es (José A. Juanes) 


\section{A global approach to mapping the environmental risk of harbours on aquatic}

\section{systems}

3 Highlights:

- A method is proposed to assess the environmental risk of commercial harbours on aquatic systems.

- The method is a tool to identify the factors of risk on harbour aquatic systems

- Results obtained from 15 globally distributed harbours are analysed

- Towards the creation of a global atlas of environmental risk of harbours on aquatic systems

\section{Graphical abstract:}

\section{Abstract:}

13 The goal of this paper is to propose a screening method for assessing the environmental risk to aquatic systems in harbours worldwide. A semi-quantitative method is based on

15 environmental pressures, environmental conditions and societal response. The method is

16 flexible enough to be applied to 15 harbours globally distributed through a multinational

17 test using standardised and homogenised open data that can be obtained for any port

18 worldwide. The method emerges as a useful approach towards the foundation of a global 
environmental risk atlas of harbours that should guide the harbour sector to develop a more globally informed strategy of sustainable development.

Keywords: environmental risk assessment; global atlas; pressure-state-response model; harbour aquatic systems; harbour management; sustainable development.

\section{INTRODUCTION}

Shipping has an important role in moving about $90 \%$ of global trade, which is vital for the continuing and sustainable development of the world economy (ICS, 2018; 2019). The shipping sector is projected to continue to expand in the future with an estimated annual growth rate of $3.2 \%$ by $2017-2022$ (UNCTAD, 2017). The relevance of this sector for world trade has placed this industry at the centre of a policy debate on globalisation, trade, development and environmental sustainability (UNCTAD, 2012). Harbours are continuing to expand to accommodate the infrastructure required to support growth in the shipping industry (UNCTAD, 2012). This growth increases the likelihood of environmental damage, which, to some extent, is being mitigated by harbour authorities embracing a sustainable development approach (EC, 2013). Shipping, alongside the many other marine activities, generates several threats of varying severity to marine ecosystems (Gómez et al., 2014; Knights et al., 2015; Valdor et al., 2017), and harbours themselves can be some of the most impacted habitats on Earth (Halpern et al., 2008).

The environmental sustainability of harbours needs to be focused on preventing the impoverishment of aquatic systems caused by pollution from commercial ships or other navigation activity. Harbours are guided and regulated by international legislation that aims to limit ecosystem exposure to harmful activities. International bodies, like the International Maritime Organisation (IMO), continue to develop legal frameworks to mitigate environmental harm as a result of commercial shipping (e.g. IMO, 2004; 2013; 2014 or Lethbridge, 1991), and they set the appropriate standards through international treaties and conventions. Others, such as the World Association for Waterborne and Transport 
47 Infrastructure (PIANC), provide expert guidance (PIANC, 2019), recommendations (PIANC,

48 2011) and technical advice (PIANC, 2020) on environmental issues related to both

49 recreational and commercial navigation activity (Brolsma, 2010). The maintenance of high-

50 quality aquatic systems (e.g. by preventing marine pollution) is a permanent and universal

51 goal of these conventions, guidelines and the research developed by these international

52 organisations. Consequently, water quality has been one of the top 10 environmental

53 priorities of the harbour sector over last years (2003-2009) (ESPO-ECOPORTS, 2019).

55 Scientific research that provides an evidence-based for decision-making related to

56 environmental risk on harbour aquatic systems is conducted by projects like the World

57 Harbour Project (WHP) (www.worldharbourproject.org, Steinberg et al., 2016). This project

58 enhances research and management across major urban harbours. To develop resilient

59 urban harbours, a global network of collaborating scientists works on different topics such

60 as ecological engineering (Strain et al., 2019), environmental management (Valdor et al.,

61 2019), accessible syntheses and summaries of current knowledge (e.g. Juanes et al.,

62 2020). Thus, research programs should be responsible in developing science and

63 communicating findings in an accessible way to a wide range of users to facilitate the

64 design of global strategies. We suggest that global strategies are needed to ensure that

65 harbour managers worldwide are able to assess the environmental risk on aquatic

66 systems using an easy-to-apply and versatile method. In this context, one of the main

67 objectives of global strategies is to provide standardised methods to analyse risk. In this

68 way, data among different harbours are comparable, and their management can be

69 adjusted to the best available practices regarding limiting environmental risk.

70

71 However, when global strategies are designed, the harbours' histories, the

72 geomorphological and environmental contexts and the socio-economic settings are very

73 different across the world (Steinberg et al., 2016) and thus may affect approaches to

74 environmental management. In that context, the Environmental Risk Assessment (ERA) 
75 arises as a general management tool that is used worldwide to assess potential effects on

76 the environment due to the exposure to disturbing agents derived from different human

77 activities (e.g. fishery, industry, urban, agricultural or harbour activities, among others)

78 (AENOR, 2008; Hope, 2006; Smith et al., 2007; Samhouri and Levin, 2012; Valdor et al., 79 2016). Using the ERA approach, the potential effects of environmental hazards on the 80 quality of aquatic systems in harbour areas have been widely studied (e.g. Ronza et al., 81 2006; Grifoll et al., 2010; Gómez et al., 2015; Ondiviela et al., 2012; Parra et al., 2018), and

82 methods to assess the environmental risks of harbour activities have been proposed (e.g.

83 Gómez et al., 2015; Juanes et al., 2013; Ondiviela et al., 2012; Puig et al., 2015; Valdor et al., 2016). However, worldwide studies to assess the environmental risk of harbour activities on aquatic systems to support global strategies, such as Global Sustainable Development Goals (United Nations, 2015), have not been conducted.

Harbours around the world implement different environmental management methods that make use of different approaches to the characterisation of systems, use different analytical tools and databases, thus making it challenging to obtain standardised quantitative data

90 globally (PIANC, 2019). For this reason, qualitative and semi-quantitative data analyses are

91 more suitable alternatives when conducting an ERA study at a global scale (Gómez et al., 2019). Moreover, parameters, indicators, and assessment criteria should be carefully selected to integrate the singularities of each specific harbour (Darbra et al., 2005; Gupta et

94 al., 2005). We suggest that, at the same time, the simplicity and low computing cost of the

95 method should allow for wider applicability to harbours of different sizes, hydrodynamic characteristics, harbour uses and pressures or resources to assess environmental 97 challenges.

99 The goal of this paper is to propose a method for mapping the assessment of the 100 environmental risk of harbours on aquatic systems. This method will be: i) flexible enough 101 to be applied to any harbour worldwide; ii) open-data dependent; and iii) implemented to lay 102 the foundation to create a global atlas of environmental risk on aquatic systems of harbours. 
103 The proposed method is tested by applying it to 15 harbours spread across five continents

104 worldwide. The main contributions of this study are: (i) the development of a standard and

105 unified ERA method to assess environmental risk of harbour activities worldwide on aquatic

106 systems (Section 2); (ii) the implementation of the ERA method in 15 harbours around the 107 world (Section 3); and (iii) the discussion of the proposed method and the results obtained 108 in the implementation (Section 4).

\section{MATERIALS AND METHODS}

110 The semi-quantitative method providing an assessment of environmental risk on aquatic 111 systems is based on the Pressure-State-Response (PSR) model defined by Gómez et al. 112 (2019) for marinas. The method comprises the following three steps: i) identification of 113 harbours and data collection; ii) estimation of the risk factors (environmental pressures of 114 harbour activities on the aquatic system, environmental conditions and management 115 responses); and iii) assessment of environmental risk.

\section{$116 \quad 2.1$ Identification of harbours}

117 Harbours are classified based on the typologies defined by the US National Geospatial118 Intelligence Agency (2015) into: i) coastal natural harbours are harbours that are sheltered 119 from the wind and sea due to their location within a natural coastline or occur in the protective 120 lee of an island, cape, reef or other natural barrier, or harbours that are located along a river; 121 ii) coastal breakwater harbours are harbours located behind a human-made breakwater that 122 are constructed to provide shelter or supplement inadequate shelter already provided by 123 natural resources; and iii) natural river harbours are harbours in which slips for vessels have 124 been excavated in the banks obliquely or at right angles to the axis of the stream.

125 For this study, general data, hydro-morphological characteristics and environmental 126 management information was gathered globally at all 15 harbours through a standardised 127 form (Supplementary Data. Appendix A) and through other sources of information (e.g., 128 official harbour webpages). 


\subsection{Estimation of environmental risk}

130 Environmental risk assessment at the harbour level was based on three factors: i) Pressures

131 from human activities exerted on the environment; ii) State, or the environmental conditions

132 that relate to the quality of the environment; and, iii) Response, or the extent to which the

133 harbour responds to environmental concerns (OECD, 2003) (Eq.1).

134 Accordingly and based on Gómez et al., (2019), environmental risk of harbours on aquatic 135 systems was estimated through the following formulas:

$136 \quad \mathrm{Ri}=$ Pti $\times$ Sti + Rsi

$137 \quad \mathrm{Ri}=(\mathrm{NVi}+\mathrm{HSi}+\mathrm{HOi}+\mathrm{CDi}) \times(\mathrm{SUi}+\mathrm{EVi}+\mathrm{NAi})+(\mathrm{AMi}+\mathrm{Ali})$

138 Where $\mathrm{R}$ is the environmental risk, $\mathrm{Pt}$ is the Pressure, $\mathrm{St}$ is the State and $\mathrm{Rs}$ is the Response 139 of an $i$ harbour. Pressure is estimated considering the navigation activity (NV), the harbour 140 services (HS), the harbour operation $(\mathrm{HO})$ and the coastal development around the harbour 141 (CD). While, State is estimated by combining the susceptibility (SU), the ecological value 142 (EV) and the naturalness (NA). Finally, Response was estimated through the adopted 143 measures (AM) and the Adopted Instruments (AI).

144 Estimation of environmental risk was evaluated using a semi-quantitative assessment 145 criteria that was based on a combination of specific indicators, representative of a number 146 of selected parameters for each factor (Table 1).

147 Table 1. Parameters, indicators, metrics and criteria assessment to estimate each environmental risk 148 factor. (i: a specific harbour; max: maximum value obtained for a parameter considering all harbours 149 under study; ISO: International Organisation for Standardisation; EMAS: Eco-Management and Audit 150 Scheme; PERS: Port Environmental Review System). Unless specifically indicated by appropriate 151 references to the source paper indicators were originally developed here.

\begin{tabular}{|c|c|c|c|}
\hline Factor & Parameter & Indicator and metric (units) & Criteria assessment \\
\hline Pressures & $\begin{array}{l}\text { Navigation } \\
\text { Activity (NV) }\end{array}$ & $\begin{array}{l}\text { Density of trade vessels } \\
\text { (vessels per year } / \mathrm{m}^{2} \text { ) by } \\
\text { dividing vessels per year by } \\
\text { the surface water area where } \\
\text { the harbour activities take } \\
\text { place. }\end{array}$ & $N V_{i} / N V_{\max }[0-1]$ \\
\hline
\end{tabular}




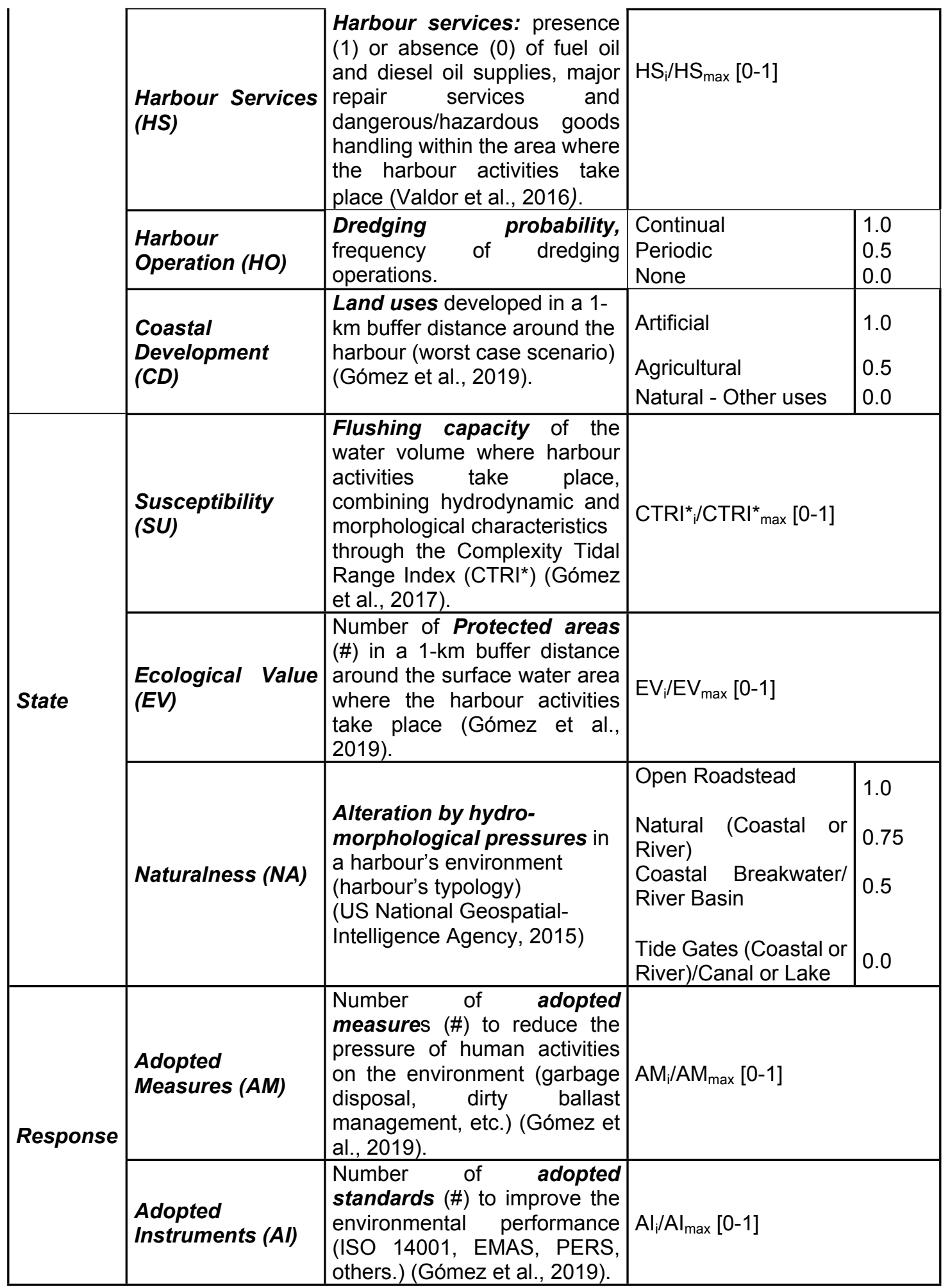

${ }^{*} C T R I_{i}=\left[1-\frac{4 \times A}{\pi \times L^{2}}\right] \times \frac{e}{R}$ Where $\mathrm{A}$ is the surface water area where the harbour activities take place $\left(\mathrm{m}^{2}\right), \mathrm{L}$ is the diameter of the smallest circle enclosing the surface water area polygon $(m), e$ is the minimum distance between the harbour's infrastructures or the natural elements that conform the harbour's entry $(\mathrm{m})$ and $\mathrm{R}$ is the medium tidal range (m) (Gómez et al., 2017). 
158 The range of the potential values of all parameters were normalised (varying from 0 to 1 ) by 159 dividing the observed value by the maximum value, after discarding outliers for each 160 parameter with values greater than $\mathrm{x} \square \pm 3 \cdot \mathrm{SD}$ (Gómez et al., 2019).

\subsection{Environmental Risk Assessment}

162 To assess the environmental risk to the harbour's aquatic systems, the results of pressure 163 and state factors were classified into four categories (1 to 4), while the response factor was 164 categorised by assigning one of either values: 0 or 4 (Table 2, Eq. 2). Levels separating the 165 different categories were established for all harbours under study using the 25th, 50th and 166 75th percentile values-with the 50th percentile value used as the threshold between optimal 167 and insufficient response (Table 2).

Table 2. Criteria to assess Pressures $\left(\mathrm{Pr}_{\mathrm{i}}\right)$, State $\left(\mathrm{St}_{\mathrm{i}}\right)$ and Response $\left(\mathrm{Rs}_{\mathrm{i}}\right)$ categories from study site 170 results (VL: Very low; L: low; M: moderate; H: high; P25: 25th Percentile; P50: 50th Percentile; P75: 171 75th Percentile).

\begin{tabular}{|c|c|c|c|}
\hline Factor & Category & Criteria & Thresholds \\
\hline \multirow{5}{*}{$\begin{array}{l}\text { Pressures } \\
\text { (Pr) }\end{array}$} & VL (1) & Pri $\leqslant P_{25}$ & Pri $\leqslant 2 . I I$ \\
\hline & $L(2)$ & $\mathrm{P}_{25}<\operatorname{Pri} \leqslant \mathrm{P}_{50}$ & $2 . \mathrm{II}<\operatorname{Pri} \leqslant 2.5 \mathrm{I}$ \\
\hline & M (3) & $\mathrm{P}_{50}<$ Pri $\leqslant \mathrm{P}_{75}$ & $2.5 \mathrm{I}<$ Pri $\leqslant 2.58$ \\
\hline & $\mathrm{H}(4)$ & Pri > P75 & Pri > 2.58 \\
\hline & $\mathrm{VL}(1)$ & Sti $\leqslant P_{25}$ & Sti $\leqslant 0.95$ \\
\hline \multirow[t]{3}{*}{ State (St) } & $L(2)$ & $\mathrm{P}_{25}<\mathrm{Sti} \leqslant \mathrm{P}_{50}$ & $0.95<$ Sti $\leqslant$ I.IO \\
\hline & $M(3)$ & $\mathrm{P}_{50}<$ Sti $\leqslant \mathrm{P}_{75}$ & I.IO $<$ Sti $\leqslant$ I. 37 \\
\hline & $\mathrm{H}(4)$ & Sti > P75 & Sti > 1.37 \\
\hline \multirow[t]{2}{*}{ Response (Rs) } & Optimal (0) & Rsi $\geq$ P50 & Rsi $\geq 0.75$ \\
\hline & Insufficient (4) & Rsi < P50 & Rsi $<0.75$ \\
\hline
\end{tabular}

174 Obtained scores at the factor level (Table 2) were used to estimate the environmental risk

175 of each harbour through Eq. 1. Based on the environmental risk value (Eq. 1), each harbour 
176 was classified considering three categories: (i) high-risk harbour ( $R \mathrm{i} \geq 12)$, (ii) moderate-risk 177 harbour $(6 \leq \mathrm{Ri}<12)$, (iii) low-risk harbour $(1 \leq \mathrm{Ri}<6)$.

\section{RESULTS}

\subsection{Identification of harbours}

The twenty-seven partners of World Harbour Project network were invited to participate to test the developed ERA method (Steinberg et al., 2016). Fifteen WHP partners were able to encourage harbour managers from their respective cities to participate and to gather the needed information. WHP partners contacted harbour managers by email or phone, and meetings were conducted when necessary. The fifteen harbours, where the developed ERA method was tested, spanned Europe (Dublin, Heraklion, Plymouth, Santander, Ravenna and Vigo), Australasia (Ashdod, Auckland, Darwin, Hobart, Hong Kong, Qingdao and Sydney) and the Americas (Baltimore and Rio de Janeiro) (Figure 1). "Coastal natural harbour" was the typology best represented by seven harbours (Rio de Janeiro, Qingdao, Hong Kong, Santander, Vigo, Darwin and Sydney), followed by "coastal breakwater harbours" represented by four harbours (Ashdod, Dublin, Heraklion, and Ravenna) and

91 "natural river harbours" represented by four harbours (Baltimore, Plymouth, Auckland and Hobart) (Figure 1).

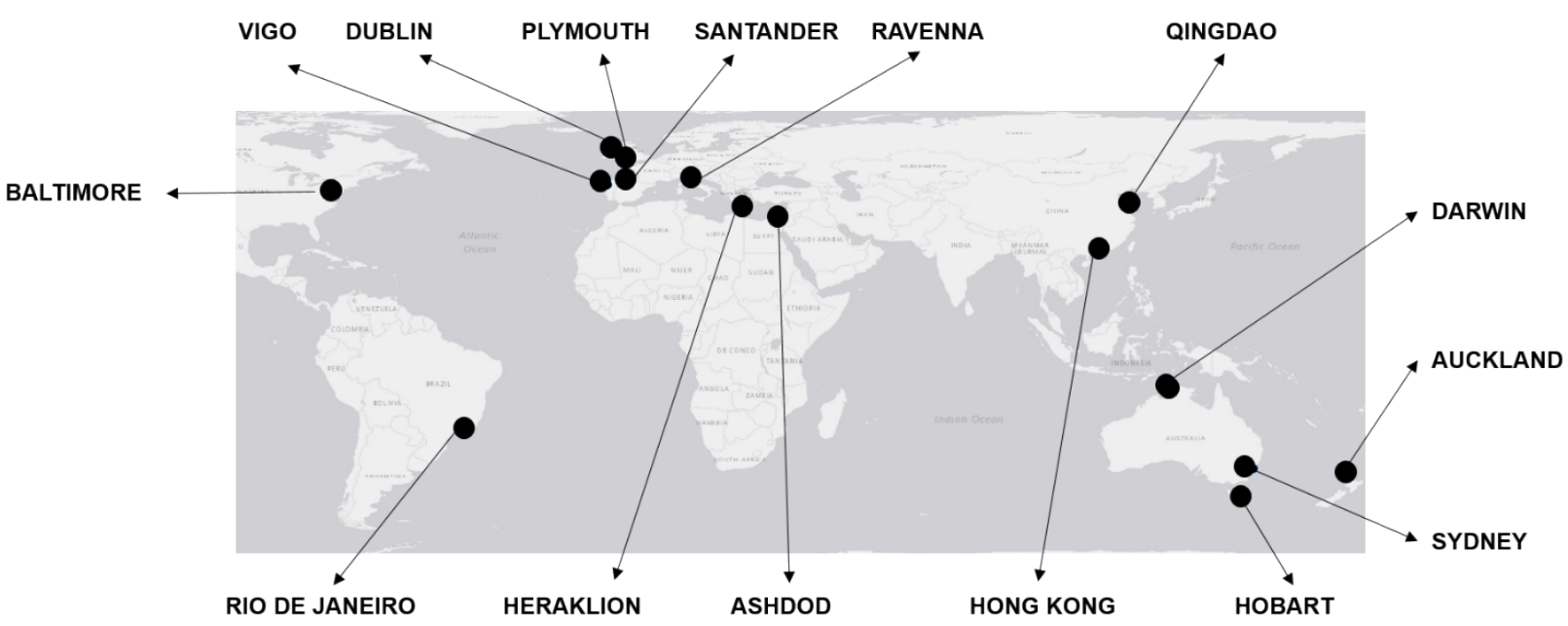

194 Figure 1. Harbours assessed using the ERA method. 
195 The standardised form (Appendix A) was used to gather information from harbour 196 managers. Harbour managers sent the filled-in form through email to their respective local 197 WHP partner. In addition to consulting with harbour managers, where possible, data 198 collected was cross-checked using global, national (e.g. puertos.es) and local resources or 199 was specifically sourced from each harbour (e.g. the official web page of each harbour). 200 Using these sources of information, a database of metrics was generated for each harbour.

\subsection{Estimation of environmental risk}

202 The environmental risk assessment process provided explicit information on the parameters 203 of risk. To define the spatial scope, a polygon of the surface area of the water where harbour 204 activities take place was first digitalized using ArcGIS software. Harbour managers were 205 asked to approve the delimitation of these areas. The resulting polygons indicated harbour 206 surface-water areas (Supplementary data. Appendix B). The tools "extract by mask" and

207 "Clip" from the ArcGIS software were used to recognize both land uses and protected areas 208 in 1-km buffer around each harbour, using Globe Land 30 (Chen et al., 2015) and World 209 Database on Protected Areas (UNEP-WCMC, 2016), respectively. Mean tidal range (R, m), 210 as a hydrodynamic characteristic, was calculated from the GOS dataset (Cid et al., 2014); 211 morphological characteristics were estimated for each harbour using ArcGIS techniques, 212 including area $\left(A, m^{2}\right)$, applying the "calculate geometry" tool; length ( $\left.L, m\right)$ and entrance 213 width (e, m), using the "minimum bounding geometry" tool (Gómez et al., 2017).

214 Pressures: Normalised values of navigation activity (NV) were extremely variable among the 215 studied harbours. Ashdod had the highest density of trade vessels (1), followed by Ravenna 216 (0.18), Dublin (0.16), Qingdao (0.15) and Rio de Janeiro (0.11), while the other harbours 217 showed normalised values lower than 0.07 (Figure 2, NV). Most harbour areas showed the 218 maximum value of Harbour Services (HS), since 10 of the 15 study sites develop fuel oil and 219 diesel oil supplies, major repair services and dangerous or hazardous goods handling 220 activities (Figure 2, HS). Exceptions to this were Hobart and Plymouth, where fuel oil supply 
221 and major repairs are not developed, and Heraklion and Ravenna, where dangerous or 222 hazardous goods handling is not carried out. Harbour Operation (HO) was estimated 223 through dredging activities, which is are periodic operation-in most of the harbours (0.5) 224 apart from Ashdod and Hong Kong, where continual dredging operations are undertaken 225 (1), and Hobart and Qingdao, where dredging operations are not carried out (Figure 2, HO). 226 Normalised Coastal development scored 1 in nearly all the harbours, since the land use 227 around the harbours was mainly artificial (urban, mining or industrial). Only one harbour 228 (Darwin) presented natural land uses in its surroundings (Figure 2, CD).

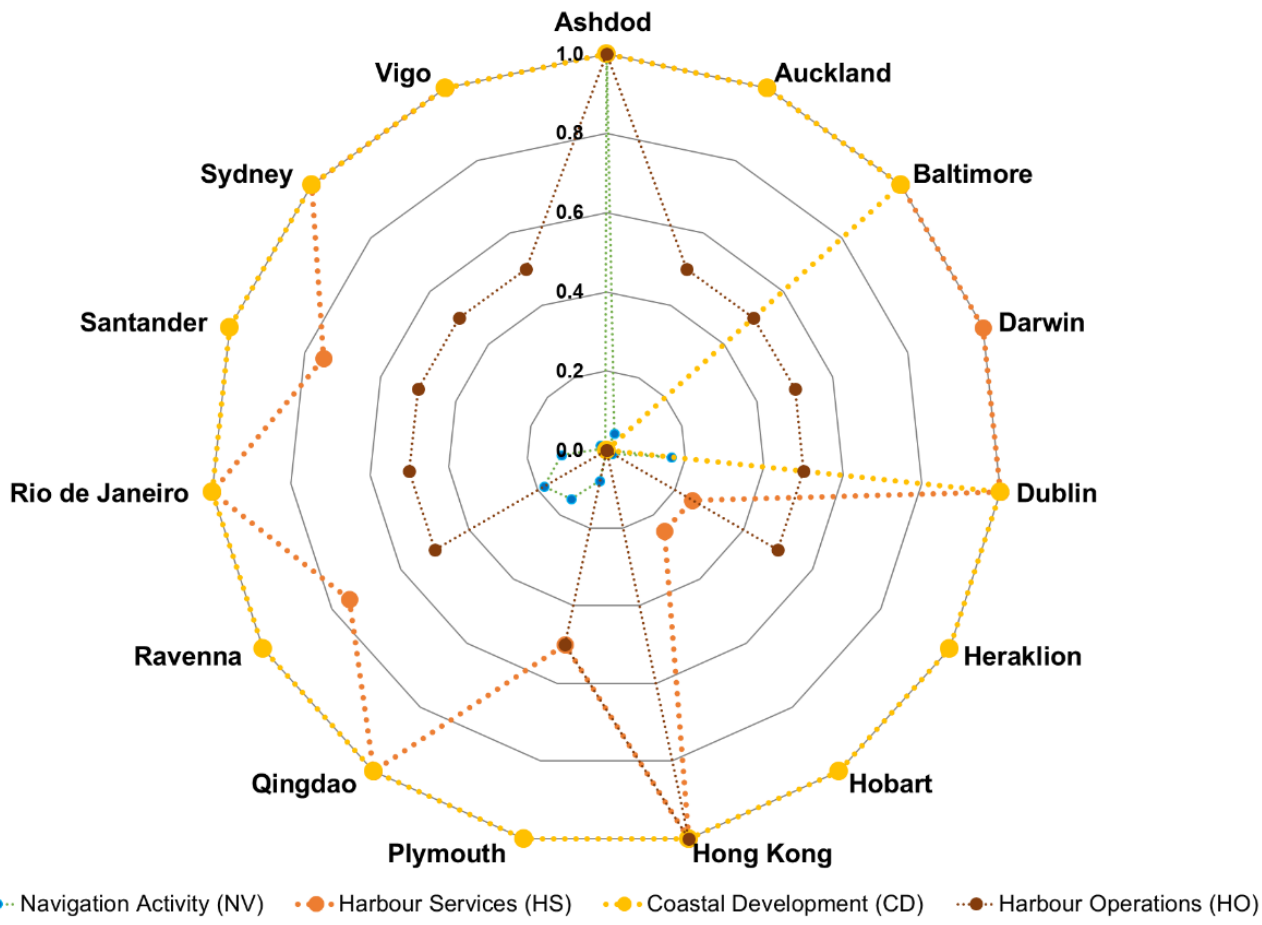

State: Susceptibility (SU, a measure of flushing capacity) was the most variable parameter of State in all the 15 harbours studied (Figure 3, SU) as it is related to the cleaning capacity 235 of the water volume, which combines hydrodynamic and morphological characteristics at 236 the harbour level. The main characteristics of the harbours that were responsible for this variability were the differences in water surface area $\left(\sim 0.8 \mathrm{~km}^{2}\right.$ in Plymouth, to $36.73 \mathrm{~km}^{2}$ in 
238 Darwin), the minimum distance between the elements that conform the harbour's entry $(\sim 0.2$

$239 \mathrm{~km}$ in Ravenna to $\sim 316 \mathrm{~km}$ in Darwin) and the variability in tidal ranges (microtidal in the

240 Mediterranean to a $5 \mathrm{~m}$ tidal range in Plymouth). Regarding the Ecological Value (EV), the

Response: All studied harbours implemented a minimum of 3 Adopted Measures (AM) to reduce the pressures of human activities on the environment (AM normalised value $\leq 0.5$ ),

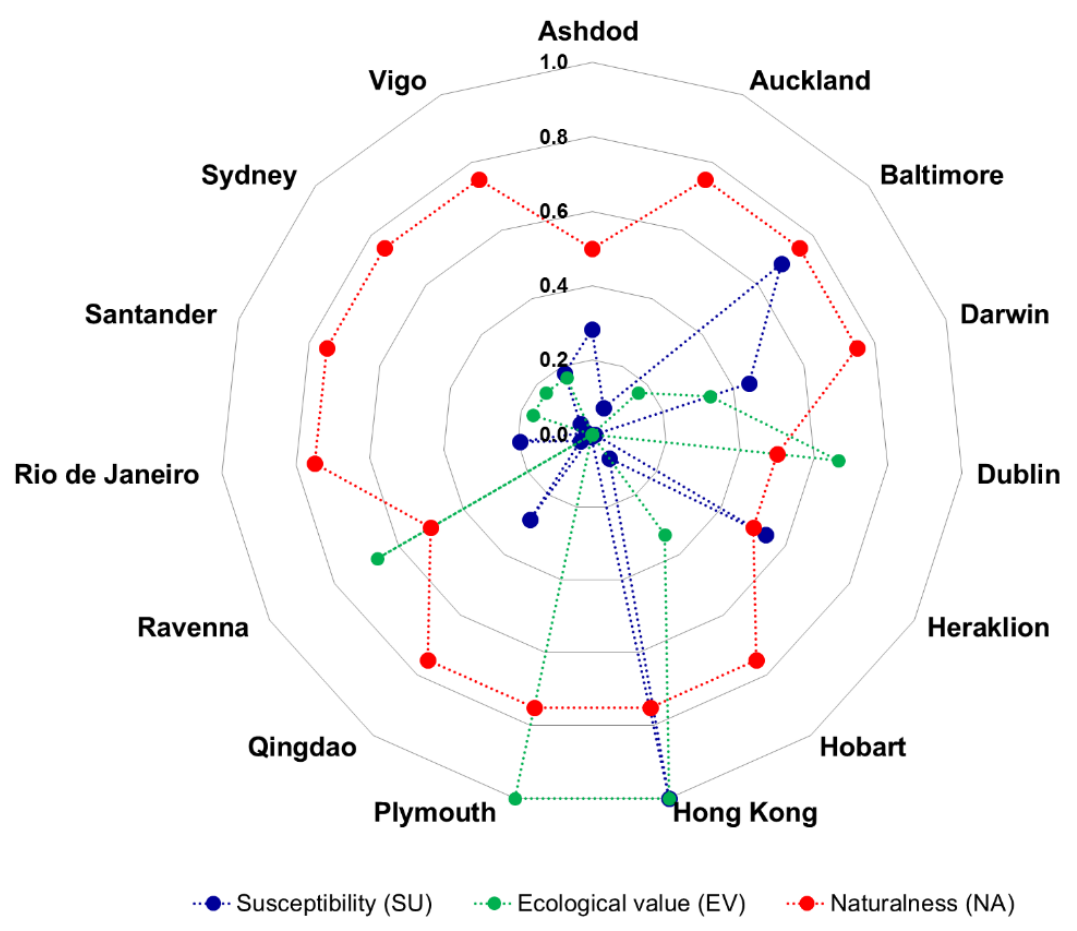

Figure 3. Representation of normalised values of the parameters applied for the estimation of environmental conditions (State) at each of the 15 studied harbours. with 8 being the maximum number of measures applied in Qingdao and Baltimore (1 AM normalised value) (Figure 4, AM). A higher variability was registered in the number of 254 Adopted Instruments (Al), with eight harbours where no instruments to achieve international 
255 standards were applied, four harbours where 1 was adopted, two harbours where 2

\subsection{Environmental risk assessment}

264 pressure with four harbours assessed as being moderate. This was followed by a total of six 265 harbours that were assessed as having low environmental pressures and, finally, three 266 harbours with very low associated pressures (Figure 5, Pressures in blue bars). Regarding 267 the State factor, four harbours were classified within the high category, with three harbours 268 showing moderate environmental conditions and a total of eight harbours within the low and 269 very-low categories (Figure 5, State in yellow bars). Finally, 7 of the 15 studied harbours 270 showed insufficient environmental management, while 8 harbours presented an optimal level of management Response (Figure 5, Response in green bars). 
272 The most frequent category of risk was moderate; 8 of the 15 harbours studied presented

273 moderate risk, 5 harbours presented low risk, while 2 harbours presented a high

274 environmental risk to aquatic systems (Figure 5, Environmental risk in red bars).

278

279

280

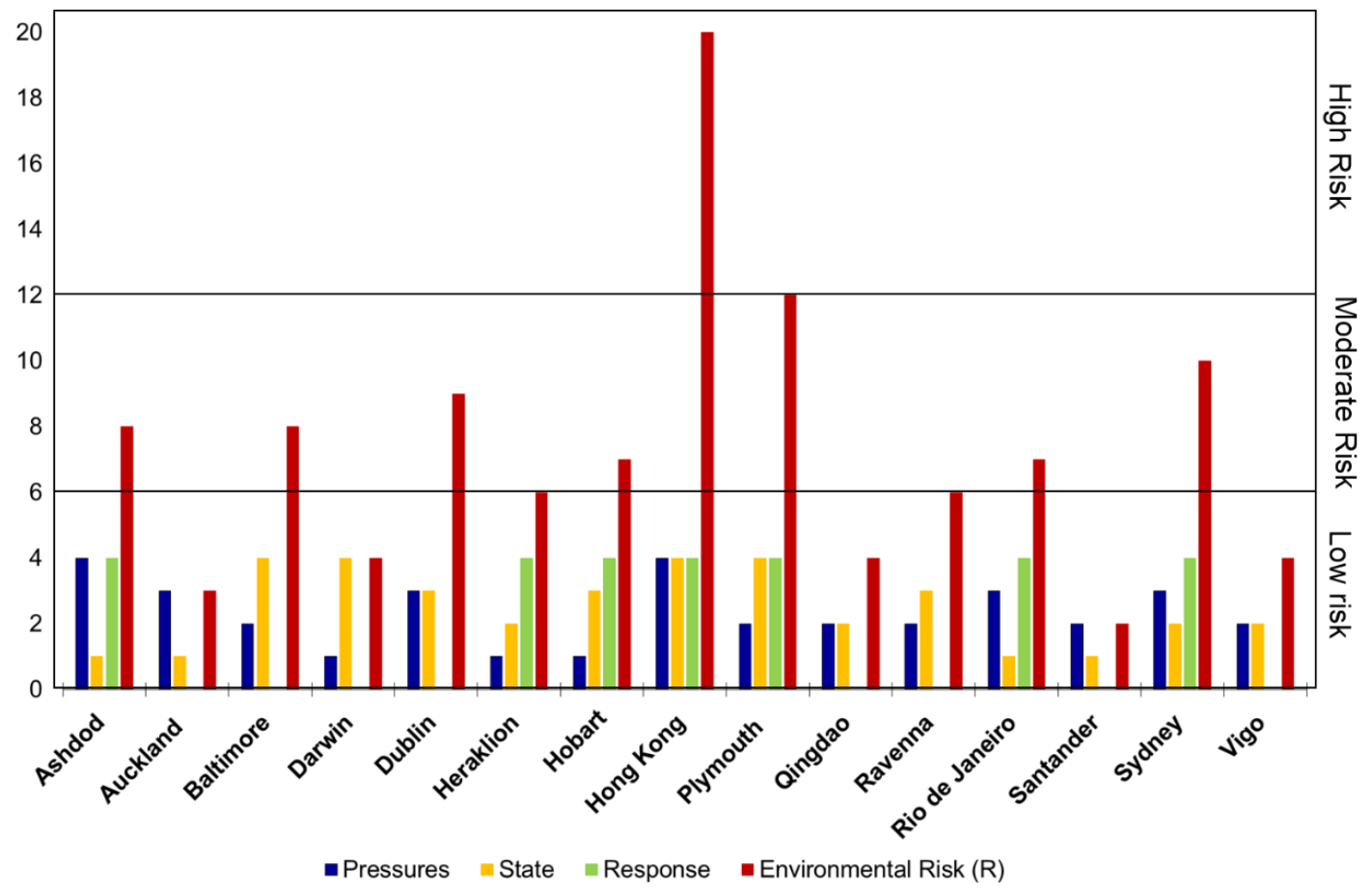

Figure 5. Graphical representation of categorised risk factors (Pressures, State and Response) and categorised environmental risk to aquatic systems at each of the 15 studied harbours.

Results of environmental risk to aquatic systems of harbours, based on this study's results are shown in Supplementary data Appendix B.

\section{DISCUSSION}

\subsection{Why this ERA method?: The conceptual model}

From a conceptual point of view, the Pressure-State-Response (PSR) model (OECD, 2003)

is used as a framework to select indicators that assess environmental risk at the harbour level, based on Gómez et al., (2019). Moreover, the Driving force-Pressure-State-ImpactResponse (DPSIR) model (EEA, 2005) is integrated in the PSR model to define specific indices of Pressure, State and Response. These indices group and classify a small number of indicators (Figure 6). 
289 From a practical point of view, the selection of general-purpose indicators for global 290 assessments was complex because of the need to obtain homogeneous, objective and 291 systematic, open and publicly available data and information on a series of diverse 292 parameters from analogous entities (harbours) that are under different socio-ecological 293 contexts from all over the world. Indicators were selected based on: i) the complementarity 294 and non-redundancy of indicators in their representation of risk factors; ii) the possibility of 295 finding available and homogeneous data from harbours worldwide, and iii) state-of-the-art 296 and previous studies.

298 Driving forces describe the social, demographic and economic development within a given 299 harbour (EEA, 2005). Based on the conceptual model presented (Figure 6), indicators 300 selected to estimate the environmental pressures include the four main driving forces 301 relevant to the harbour areas (navigation, harbour services, harbour operation and coastal 302 development). Navigation activity, estimated as the number of trade vessel visits per year 303 by a water-surface area of a harbour, was selected, as it has been identified in previous 304 works as a representative environmental stressor (Antão et al., 2016) and it is easily 305 accessible from institutional statistics (e.g. Eurostat, or individual webpages of harbours). 306 Regarding Harbours Services (HS), two indicators were selected: i) major repair services 307 (shipyards, ship repair or painting, etc.) that generate chemical wastes (heavy metals, PAHs 308 and antifoulants), which can pose a risk to aquatic organisms inhabiting harbour areas 309 (Bebianno et al., 2015); and ii) dangerous/hazardous goods handling defined by IMO codes 310 (IMO, 2014), which were previously considered in ERA mapping studies on harbour systems 311 (e.g. Valdor et al., 2016). Furthermore, dredging, one of the most important operations and 312 maintenance activities within harbours (PIANC, 2006), and dominant land use in the 313 surrounding area, served as proxies of the external influences on water quality (Cornelissen 314 et al., 2008). 
316 Indirect or direct pressures are identified by each driving force (Gómez et al., 2019). The

317 identified pressures produce impacts altering the state of the environment (Ondiviela et al.,

319 harbour's environment: susceptibility, ecological value and naturalness. From the eight

320 pressure indicators proposed in the conceptual model (Figure 6), there are three related to

321 quality of the aquatic system (chemical quality, physico-chemical quality and biological

322 quality) that require periodic monitoring and systematic evaluation. Since each country

323 applies different monitoring and evaluation systems (in terms of thresholds, frequency, etc.),

324 the susceptibility to water and sediment contamination was considered as a standard

325 representative indicator of the quality of the aquatic system of harbours worldwide, assuming

326 a significant relationship between flushing capacity and water quality in littoral areas

327 (Ferreira et al., 2005; Fortes and Silva., 2006; Gómez et al, 2014; Yin et al., 2000). This

328 assumption was previously used for ERA in marinas (Gómez et al., 2017) and harbours

329 (Gómez et al., 2015). The harbour's ecological value considered that the greater the

330 protected area in the vicinity of the harbours is, the greater the biodiversity and ecological processes that maintain that system (Gómez et al., 2015; Langanke et al., 2005; Margulles

332 and Usger, 1981). Finally, their 'naturalness' (Machado, 2004) was estimated using the 333 harbour typology (US National Geospatial-Intelligence Agency, 2015) as a surrogate of 334 number and dimensions of hydro-morphological pressures at the marina level typology 335 (Gamito, 2008; Gómez et al., 2019).

337 The response factor to environmental risk was used to integrate the actions and reactions, 338 intended to mitigate, adapt to or prevent human-induced negative effects on the environment 339 that could be applied to minimize the impacts of driving forces and improve the state of 340 aquatic ecosystems (OECD, 2003). Responses may arise from different sectors, such as 341 those in social, technical or institutional (i.e. local, national or international administrations) 342 realms (Figure 6). Among all of them, institutional responses are the option that integrates 343 a greater number of fields involving social responses (awareness campaigns), institutional 
344 responses (policy and strategies) and technical responses (research). For this reason, the

45 implementation of different kinds of well-known international measures (e.g., garbage

346 disposal, oil recycling, ballast water management, among others) and international

347 standards (e.g. EMAS, ISO, PERS, among others) was considered an appropriate indicator

48 to estimate the response factor.

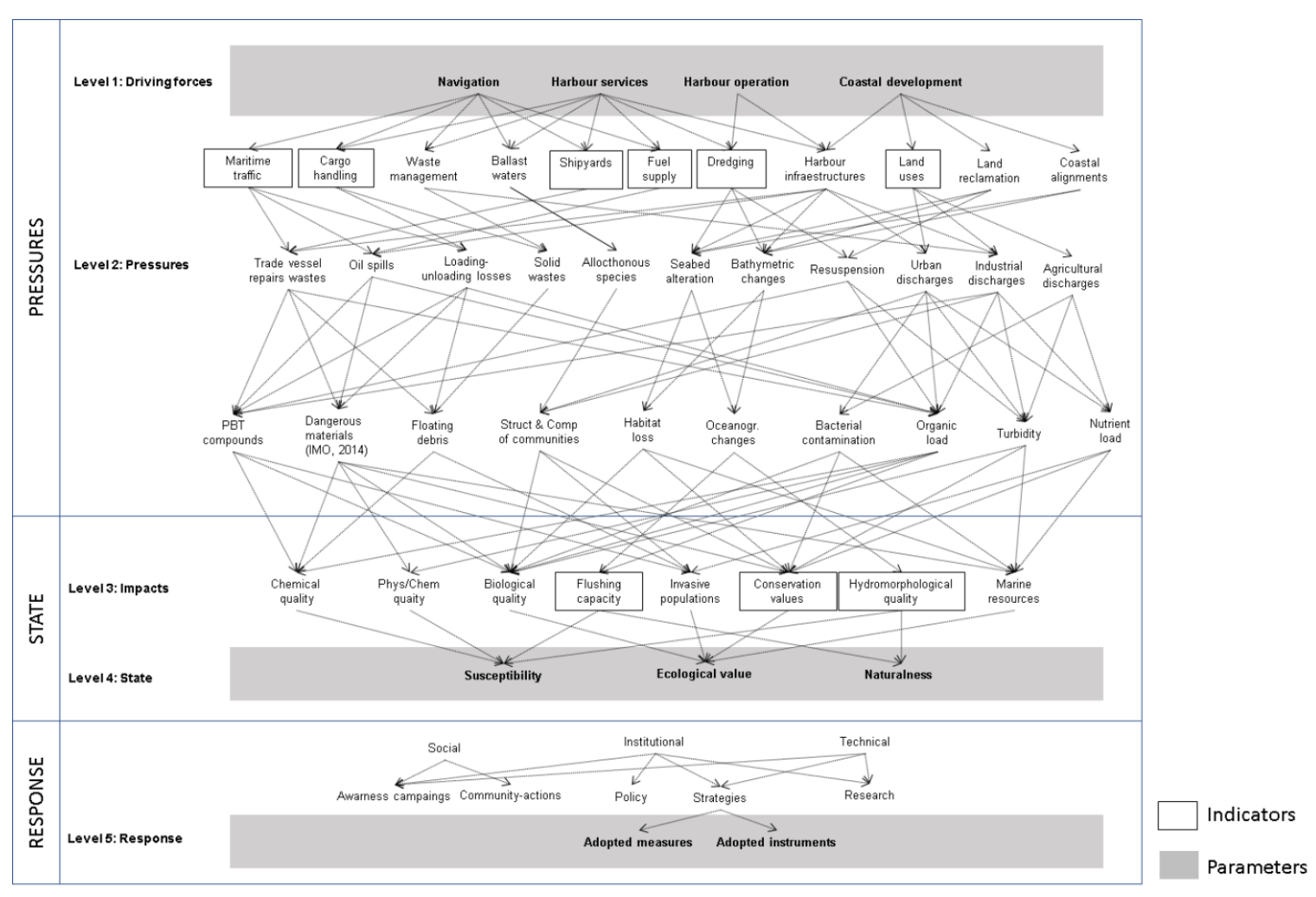

Figure 6. Conceptualisation of the causal links between main driving forces, pressures, impacts, state and response of aquatic systems in harbours.

\subsection{The global implementation}

Based on this study's results, the method used provides a tool to standardize the assessment of environmental risk to aquatic systems at a global scale (Supplementary data Appendix B). However, a question arose from this implementation: Are the PSR and DPSIR scenarios of the study sites representative of the environmental risks of harbours globally? ERA results showed that most of the study areas had a moderate risk but included significant variability of environmental pressures, environmental conditions and societal responses. However, results showed differences at the indicator level in those harbours within the same 
361 category of risk. For instance, Hobart showed a moderate environmental risk on the aquatic

362 system due to a combination of high vulnerability (high naturalness but a moderate ecological value of the surroundings) with a high score of environmental management (due

364 to the low number of adopted measures and none of the international standards 365 implemented). Heraklion showed a moderate risk on the aquatic system even though they 366 were adopting a good number of environmental measures (above the average) to reduce 367 the pressure of human activities on the environment because no international environmental 368 management instruments were applied. In other cases, the higher susceptibility (Baltimore) 369 or the higher ecological value (Ravenna), were the parameters of risk that penalised the 370 result for these harbours. Identification of such risk parameters allows for the targeted 371 application of more preventive and corrective management actions to help reduce 372 environmental risk to aquatic systems for those specific harbours.

373 Therefore, from a practical perspective, the environmental risk assessment method can be 374 used as a tool to proactively identify the most important factors of risk on which to apply 375 actions that allow for environmental improvements in each.

376 For this, expert knowledge on environmental risk is not strictly necessary, but a deep 377 understanding on the environment harbour characteristics is needed. These data are 378 controlled and known by harbour managers. In Section 2, practical steps are described 379 considering parameters, indicators, metrics and criteria to estimate each risk factor. The 380 pathway to apply the ERA method to an individual harbour include the collection of the 381 information needed and the calculation of parameters for each risk factor. A standardized 382 form to gather the information is provided in Appendix $A$ and calculations described at 383 Section 2 are easy to apply with a basic knowledge of spatial analysis using geographical 384 information systems.

385 Once applied, the method can be used to detect which harbours should apply environmental 386 measures or/and international standards to improve their management of aquatic systems, 387 based on the highest standards of environmental quality applied around the world. An 388 example of this is shown in Figure 7, which represents the hypothetical case in which the 15 
389 harbours analysed for this implementation applying eight environmental measures (such as

390 garbage disposal, dirty ballast management, waste management, bilge management, sewer pump-out, oil management) and 1 international standard (Figure 7). As all harbours apply 392 the maximum number of environmental measures and standard certifications, the value of 393 the response factor is 0 (optimal response) for all the harbours analysed. For this reason, 394 the green bars are not observed in Figure 7.

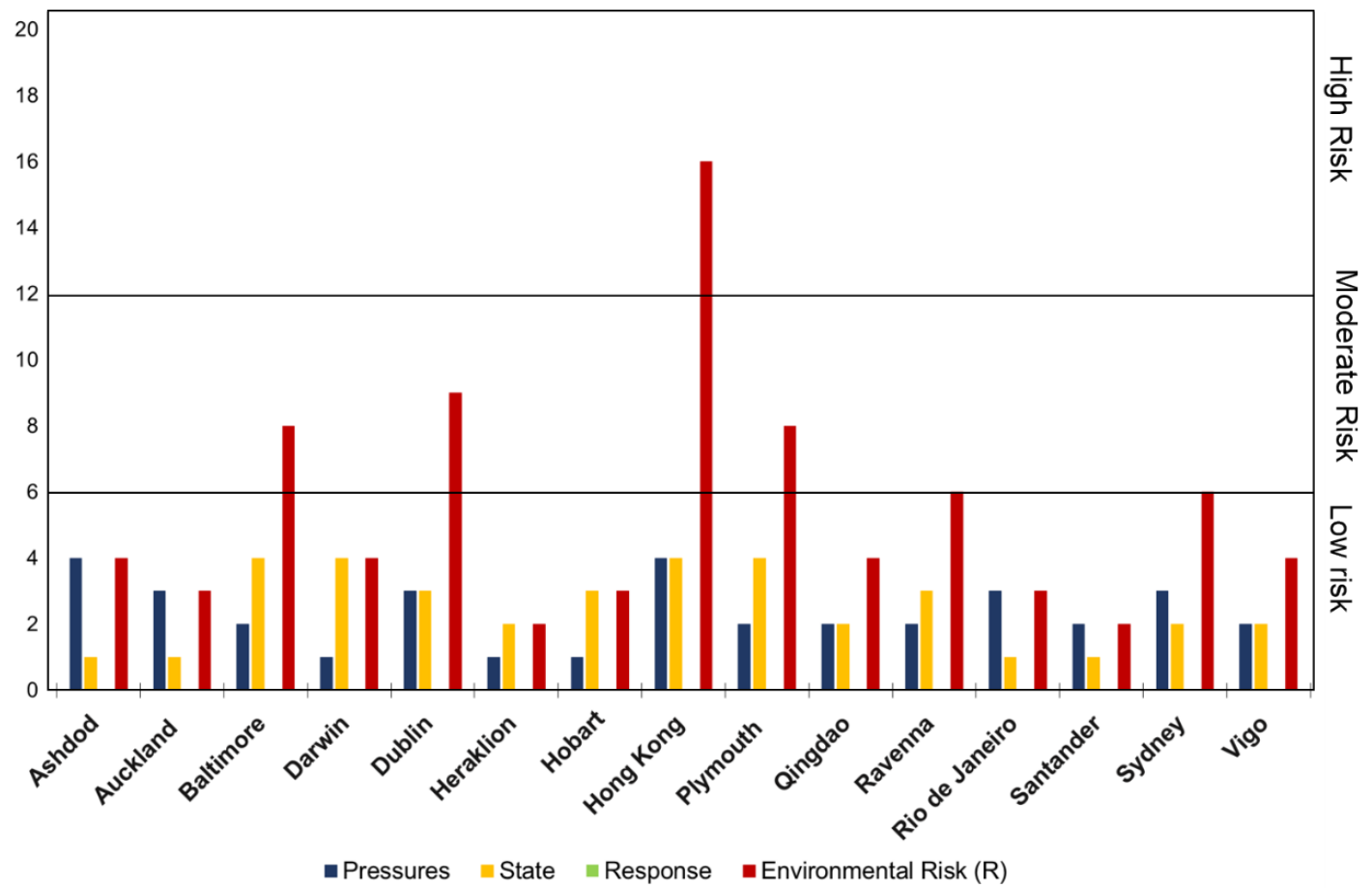

Figure 7. Graphical representation of a hypothetical situation at each of the 15 studied harbours with reduced categorised risk factors (pressures, state and responses) by the application of at least 4 environmental measures and 1 international standard and categorised environmental risk to aquatic systems.

400 In this case, one harbour continues to show high risk, five harbours show moderate risk 401 while the other nine show a low environmental risk on the aquatic system. The screening 402 capacity of this tool may address the global challenge of standardizing methods that produce 403 comparable risk assessments of high-level entities (e.g. harbours) at large spatial scales.

404 However, if the harbours applying the environmental measures and certifications do not 405 obtain a low value of environmental risk, they should then focus their efforts on reducing the 
406 environmental risk factors that are penalizing the final value of environmental risk. This is

407 the case in Hong Kong, which has high pressures due to the presence of intense navigation

408 activity (NV), the harbour services (HS) provided in the harbour, the continual dredging

409 activity (DG) in the harbour area and the Coastal development (CD) in their surroundings.

410 Baltimore is also highly susceptible probably due to the morphological characteristics of the 411 harbour area, which is very difficult to change from an environmental management 412 standpoint. In these cases, socio-economic issues should also be incorporated into a long413 term sustainability or management plan, which must assess the disadvantages and benefits 414 that may result from modifying factors that penalized the final value of the environmental 415 risk.

417 To the extent that harbours collaborate by providing the necessary information for the 418 calculation of environmental risk, it will be possible to create a global atlas of risk. 419 Collaboration by harbours will be feasible as long as the global atlas were understood as a 420 participatory process towards the sustainability of aquatic systems, recalling the adoption of 421 the 2030 Agenda and its Sustainable Development Goals (SDG, in particular SDG 14) and 422 the more recent resolution of the UN on the Decade for Ocean Sciences (2021-30), which 423 will provide a unifying framework across the UN system to enable countries to achieve all of 424 their ocean-related Agenda 2030 priorities (IOC, 2017).

426 The global atlas developed by using the method presented herein would introduce valuable 427 bring the elements of judgment to guide managers involved in decision-making (AENOR, 428 2008) towards the sustainability of aquatic systems in harbour areas, as well as to design 429 the first global strategy for sustainability related to the water quality at a global level. 430 Sustainable development goal (SDG) 14 in the UN 2030 Agenda requires to "conserve and 431 sustainably use the oceans, seas and marine resources for sustainable development" 432 (United Nations, 2015). Global Sustainable development goals require global analysis of the 433 problems presented and definition of global strategies to resolve them. Many critical 
434 management and conservation challenges of aquatic systems in harbour areas are

435 inherently spatial issues (Valdor et al., 2016). As new spatial data are collected on the distribution and intensity of harbour activities, this will allow for more flexible and adaptive

438 possible sustainable solutions through an environmental risk assessment approach.

440 Future work could improve the current Atlas through the collection and comparison of more 441 data from more harbours across the globe, and it also could test for the robustness of this 442 approach. In addition, new indicators could be developed to improve the method proposed. 443 For example, the navigation and docking of cruise ships or fishing vessels could serve as a 444 complementary indicator for the parameter of risk related to navigation activity (NV), and an 445 international connectivity index of harbours could be an indicator of the potential 446 environmental risks from invasive species.

\section{$447 \quad$ 5. CONCLUSIONS}

448 In this study, we present the first example of an Environmental Risk Assessment (ERA) 449 screening approach to assess the environmental risk on aquatic systems in harbours at 450 global scale. The method implemented in this attempt proposes a semi-quantitative and 451 simple-method to assess the environmental risk on aquatic systems in harbour areas 452 worldwide. The implementation of the method to the 15 diverse harbours has provided 453 sound evidence for the usefulness, versatility and adaptability of the proposed ERA method 454 as a management tool. The method is flexible enough to be applied to any harbour 455 worldwide using international open-databases. The implementation of this method to a wider 456 number of study cases would allow identification of harbours that could improve their 457 environmental management through the implementation of measures with specific 458 indicators. The method lays the foundation of a global atlas for the sustainability of 459 commercial-harbours and it provides a powerful tool to facilitate the design of a strategy for 460 the sustainability of the harbour sector at a global level. 


\section{Acknowledgments}

In Memoriam of Professor José Antonio Revilla Cortezón (Pepe), former leader of the

464 This work was supported by the World Harbour Project (www.worldharbourproject.org) and 465 its supporters, including The lan Potter Foundation, the NSW State Government and the 466 SIMS Foundation. Authors would like to thank all the harbour managers worldwide who 467 provided their time to complete the forms to gather relevant information for this study.

\section{Supplementary data}

469

Appendix A.

470 The appendix includes the standard form aimed to collected data from each harbour.

471 Appendix B.

472 These data include the Google map (.kml) of the Atlas of environmental risk to aquatic

473 systems in the 15 harbours analysed.

\section{REFERENCES}

475 AENOR, 2008. UNE 150008:2008. Análisis y evaluación del riesgo ambiental. $476 \quad$ AENOR. Madrid. $46 \mathrm{pp}$.

477

Antão, P., Calderón, M., Puig, M., Michail, A., Wooldridge, C., Darbra, R.M., 2016. Identification of occupational health, safety, security (OHSS) and environmental performance indicators in port areas. Saf. Sci. 85, 266-275. doi:10.1016/j.ssci.2015.12.031

Bebianno, M.J., Pereira, C.G., Rey, F., Cravo, A., Duarte, D., D’Errico, G., Regoli, F., 2015. Integrated approach to assess ecosystem health in harbor areas. Sci. Total Environ. 514, 92-107. doi:10.1016/j.scitotenv.2015.01.050

Brolsma, J.U. 2010. PIANC, The World Association for Waterborne Transport Infrastructure, an association in a changing world, 1885-2010. Brussels, Belgium. Peeters N.V. 175pp.

Chen J., Chen J., Liao A., Cao X., Chen L., Chen X., He C., Han G., Peng S., Lu M., Zhang W., Tong X., Mills J.,2015 Global land cover mapping at 30m resolution: A POK-based operational approach. ISPRS J. Photogr. Rem. Sens.103, 7-27. doi:10.1016/j.isprsjprs.2014.09.002 
Cid A., Castanedo S., Abascal A.J., Menéndez M., Medina R., 2014. A high resolution hindcast of the meteorological sea level component for Southern Europe: the GOS dataset. Clim Dyn.43, 7-8, 2167-2184. doi: 10.1007/s00382013-2041-0

Cornelissen, G., Pettersen, A., Nesse, E., Eek, E., Helland A., Breedveld, G.D., 2008. The contribution of urban runoff to organic contaminant levels in harbour sediments near two Norwegian cities. Mar. Pollut. Bull. 56, 565-573. doi:10.1016/j.marpolbul.2007.12.009

Darbra, R.M., Ronza, A., Stojanovic, T.A., Wooldridge, C., Casal, J., 2005. A procedure for identifying significant environmental aspects in sea ports. Mar. Pollut. Bull. 50. doi:10.1016/j.marpolbul.2005.04.037

EC, 2013. Ports 2030, Gateways for the TransEuropean Transport Network. European Commission. 26 pp.

EEA, 2005. EEA core set of indicators - guide. In: EEA Technical Report No 1/2005. 1725-2237. Luxembourg. 38 pp.

ESPO-ECOPORTS, 2019. European Port Industry Sustainability Report 2019. 23 $\mathrm{pp}$.

Ferreira, J.G., Wolff, W.J., Simas, T.C., Bricker, S.B., 2005. Does biodiversity of estuarine phytoplankton depend on hydrology? Ecol. Model. 187 (4), 513e523. doi: 10.1016/j.ecolmodel.2005.03.013.

Fortes, J., Silva, C., 2006. Temporal and spatial distribution of dissolved oxygen in the Ria de Aveiro lagoon. Ecol. Model. 197 (1e2), 67e88. doi: 10.1016/j.ecolmodel.2006.03.012.

Gamito, S., 2008. Three main stressors acting on the Ria Formosa lagoonal system (Southern Portugal): physical stress, organic matter pollution and the land ocean gradient. Estuar. Coast. Shelf Sci. 77, 710e720. doi:10.1016/j.ecss.2007.11.013.

Gómez, A.G., Juanes, J.A., Ondiviela, B., Revilla, J.A., 2014. Assessment of susceptibility to pollution in littoral waters using the concept of recovery time. Mar. Pollut. Bull. 81 (1), 140-148.doi: 10.1016/j.marpolbul.2014.02.004.

Gómez, A. G., Ondiviela, B., Puente, A., Juanes, J. A., 2015. Environmental risk assessment of water quality in harbor areas: A new methodology applied to European ports. J. Environ. Manage. 155, 77-88. doi: 10.1016/j.jenvman.2015.01.042

Gómez, A G., Ondiviela, B., Fernández, M., Juanes, J.A., 2017. Atlas of susceptibility to pollution in marinas. Application to the Spanish coast. Mar. Pollut. Bull.114, 239-346. doi:10.1016/j.marpolbul.2016.09.009 
Gómez, A G., Valdor, P.F., Ondiviela, B., Díaz, J.L., Juanes, J.A., 2019. Mapping the environmental risk assessment of marinas on water quality: The Atlas of the Spanish coast. Mar. Pollut. Bull.139, 355-365. doi:10.1016/j.marpolbul.2019.01.008

Grifoll, M., Jordá, G., Borja, A., Espino, M., 2010. A new risk assessment method for water quality degradation in harbour domains, using hydrodynamic models. Mar. Pollut. Bull. 60, 69-78. doi:10.1016/j.marpolbul.2009.08.030

Gupta A.K., Gupta S.K., Patil R.S., 2005. Environmental management plan for port and harbour projects. Clean Techn Environ Policy.7 (2), 133-141. doi:10.1007/s10098-004-0266-7

Halpern, B.S., Walbridge, S., Selkoe, K.A., Kappel, C.V., Micheli, F., D’Agrosa, C., Bruno, J.F., Kenneth S. C., Ebert, C., Fox, H.E., Fujita,R., Heinemann, D., S. Lenihan, Elizabeth M. P. Madin, Matthew T. Perry, Elizabeth R. Selig, Mark Spalding, H., Steneck, R., Watson, R. , 2008. A Global Map of Human Impact on Marine Ecosystems. Science, 319 (5865), 948-952. doi:10.1126/science. 1149345

Hope, B.K., 2006. An examination of ecological risk assessment and management practices. Environ. Int. 32, 983-995. doi:10.1016/j.envint.2006.06.005

ICS, 2018. International chamber of shipping. Annual Review 2018. London. 64 pp.

ICS, 2019. International chamber of shipping. Annual Review 2019. London.72 pp.

IMO, 2004. International Convention for the Control and Management of Ships' Ballast Water and Sediments (BWM). International Maritime Organization. IMO Publisher, London.7 pp.

IMO, 2013. IMSBC Code. International maritime solid bulk cargoes code and supplement, 2013 ed. International Maritime Organization. IMO Publisher, London. 558 pp.

IMO, 2014. IMDG Code. International maritime dangerous goods code. 2014 ed. International Maritime Organization. IMO Publisher, London.22 pp.

Intergovernmental Oceanographic Commission of UNESCO, 2017. Information document: International (UN) Decade of Ocean Science for Sustainable Development. "Towards the ocean we need for the future we want". Paris.23 pp.

Juanes, J. A., Ondiviela, B., Gómez, A. G., Revilla, J.A., 2013. Recommendation for Maritime Works. ROM 5.1-13. Quality of coastal waters in port areas of the Spanish National Port Administrations. Ministry of Public Works, Madrid.141 pp.

Juanes, J.A., Gómez, A.G., Rubio, S., García-Castrillo, G., Puente, A., Ondiviela, B., Medina, R. 2020. Santander Bay: Multiuse and multiuser socioecological 
568

569

570

571

572

573

574

575

576

577

578

579

580

space. Regional Studies in Marine Science, 34-101034.

DOI: $10.1016 / j . r s m a .2019 .101034$

Knights, A.M., Piet, G.J., Jongbloed, R., Tamis, J.E., Robinson, L.A., et al., 2015. An exposure-effect approach for evaluating ecosystem-wide risks from human activities. ICES J. Mar. Sci. 72, 1105-1115. doi:10.1093/icesjms/ fsu245.

Langanke, T., Rossner, G., Vrscaj, B., Lang, S., Mitchley, J., 2005. Selection andapplication of spatial indicators for nature conservation at different institutional levels. J. Nat. Conserv. 13, 101e114. doi:10.1016/j.jnc.2005.01.005

Lethbridge, J.R. 1991. MARPOL 73/78 (International Convention for the Prevention of Pollution from Ships) (English). Infrastructure notes ; no. PS-4. Washington DC : World Bank. http://documents.worldbank.org/curated/en/860841468330898141/MARPOL73-78-International-Convention-for-the-Prevention-of-Pollution-from-Ships

Machado, A., 2004. An index of naturalness. J. Nat. Conserv. 12, 95e110. doi:10.1016/j.jnc.2003.12.002.

Margules, C., Usger, M.B., 1981. Criteria used in assessing wildlife conservation potential: a review. Biol. Conserv. 21, 79e109. doi: 10.1016/00063207(81)90073-2.

OECD, 2003. Environmental Indicators. Development, Measurement and Use. The Organisation for Economic Co-operation and Development, Paris, 37pp.

Ondiviela, B., Juanes, J.A., Gómez, A.G., Samano, M.L., Revilla, J.A., 2012. Methodological procedure for water quality management in port areas at the EU level. Ecol. Indic. 13, 117-128. doi: 10.1016/ j.envsci.2013.07.001.

Parra, N.M., Nagi, A., Kersten, W., 2018. Risk Assessment Methods in Seaports: A Literature Review. Publications of the Hazard Project 24:2018.69 pp.

Petrosillo, I., Vassallo, P., Valente, D., Mensa, J.A., Fabiano, M., Zurlini, G., 2010. Mapping the environmental risk of a tourist harbor in order to foster environmental security: objective vs. subjective assessments. Mar. Pollut. Bull. 60, 1051-1058. https://doi.org/10.1016/j.marpolbul.2010.01.021. 
596 PIANC, 2011. Towards a Sustainable Waterborne Transportation Industry.

EnviCom Task Group 2. September 08, 2011.

PIANC, 2019. A Practical Guide to Environmental Risk Management (ERM) for

PIANC, 2020. Climate Change Adaptation Planning for Ports and Inland

PIANC, 2006. Environmental Risk Assessment of Dredging and Disposal Operations. PIANC Secretariat General, Brussels.40 pp.

Puig, M., Wooldridge, C., Casal, J., Darbra, R.M., 2015. Tool for the identification and assessment of Environmental Aspects in Ports (TEAP). Ocean Coast. Manag. 113, 8-17. doi:10.1016/j.ocecoaman.2015.05.007

Ronza, A., Carol, S., Espejo, V., Vílchez, J.A., Arnaldos, J., 2006. A quantitative risk analysis approach to port hydrocarbon logistics. J. Hazard. Mater. 128 (1), 10e24. doi:10.1016/j.jhazmat.2005.07.032.

Samhouri, J., \& Levin, P.S., 2012. Linking land- and sea-based activities to risk in coastal ecosystems. Biol. Conserv. 145, 118-129. doi: 10.1016/j.biocon.2011.10.021

Smith, A.D.M., Fulton, E.J., Hobday, A.J., Smith, D.C., Shoulder, P., 2007. Scientific tools to support the practical implementation of ecosystem-based fisheries management. ICES J. Mar. Sci. 64, 633-639. doi:10.1093/icesjms/fsm041

Steinberg, P.D., Airoldi, L., Banks, J., Leung, K.M.Y., 2016. Introduction to the special issue on the World Harbour Project. Reg. Stud. Mar. Sci., 8 (2), 217219. doi:10.1016/j.rsma.2016.10.001

Strain E, Alexander K, Kienker S, Morris R, Jarvis R, Coleman R, Bollard B, Firth L, Knights A, Grabowski J. 2019. Urban blue: a global analysis of the factors shaping people's perceptions of the marine environment and ecological engineering in harbours. SciTotal Environ 658:1293-1305. https://doi.org/10.1016/j.scitotenv.2018.12.285

UNCTAD, 2012. Review of Maritime Transport 2012. United Nations. New York and Geneva. United Nations.196 pp.

UNCTAD, 2017. Review of maritime transport 2017. United Nations Conference on Trade and Development Review. New York and Geneva.130 pp. 
UNEP-WCMC, 2016. World Database on Protected Areas. United Nations Environment World Conservation Monitoring Centre - World Commission on Protected Areas (https://www.protectedplanet.net/).

United Nations, 2015. Transforming our world: the 2030 Agenda for Sustainable Development. General Assembly 70 Session, 16301 (October), 1-35. doi:10.1007/s13398-014-0173-7.2

US National Geospatial-Intelligence Agency, 2015.World Port Index, Pub 150. 250 pp.

Valdor, P.F., Gómez, A.G., Ondiviela, B., Puente, A., Juanes, J.A., 2016. Prioritization maps: the integration of environmental risks to manage water quality in harbor areas. Mar. Pollut. Bull., 111 (1-2) 57-67.doi: 10.1016/j.marpolbul.2016.07.028

Valdor, P.F., Puente, A., Gómez, A.G., Ondiviela, B., Juanes, J.A., 2017. Are environmental risk estimations linked to the actual environmental impact? Application to an oil handling facility (NE Spain). Mar. Pollut. Bull. 114, 941951. doi:10.1016/j.marpolbul.2016.10.078

Valdor, P.F., Gómez, A.G., Juanes, J.A., Kerléguer, C., Steinberg, P., Tanner, E., MacLeod, C., Knights, A.M., Seitz, R.D., Airoldi, L., Firth, L.B., Crowe, T., Chatzinikolaou, E., Smith, A., Arvanitidis, C., Burt, J.A., Brooks, P.R., Ponti, M., Soares-Gomes, A., Ovejero, A., Méndez, G., 2019. A global atlas of the environmental risk of marinas on water quality. Mar. Pollut. Bull. 149, 110661. doi:10.1016/j.marpolbul.2019.110661

Yin, J., Falconer, R.A., Che, Y., Probert, S.D., 2000.Water and sediment movements in harbours. Appl. Energy 67, 341e352. PII: S03062619(00)00030-1. 


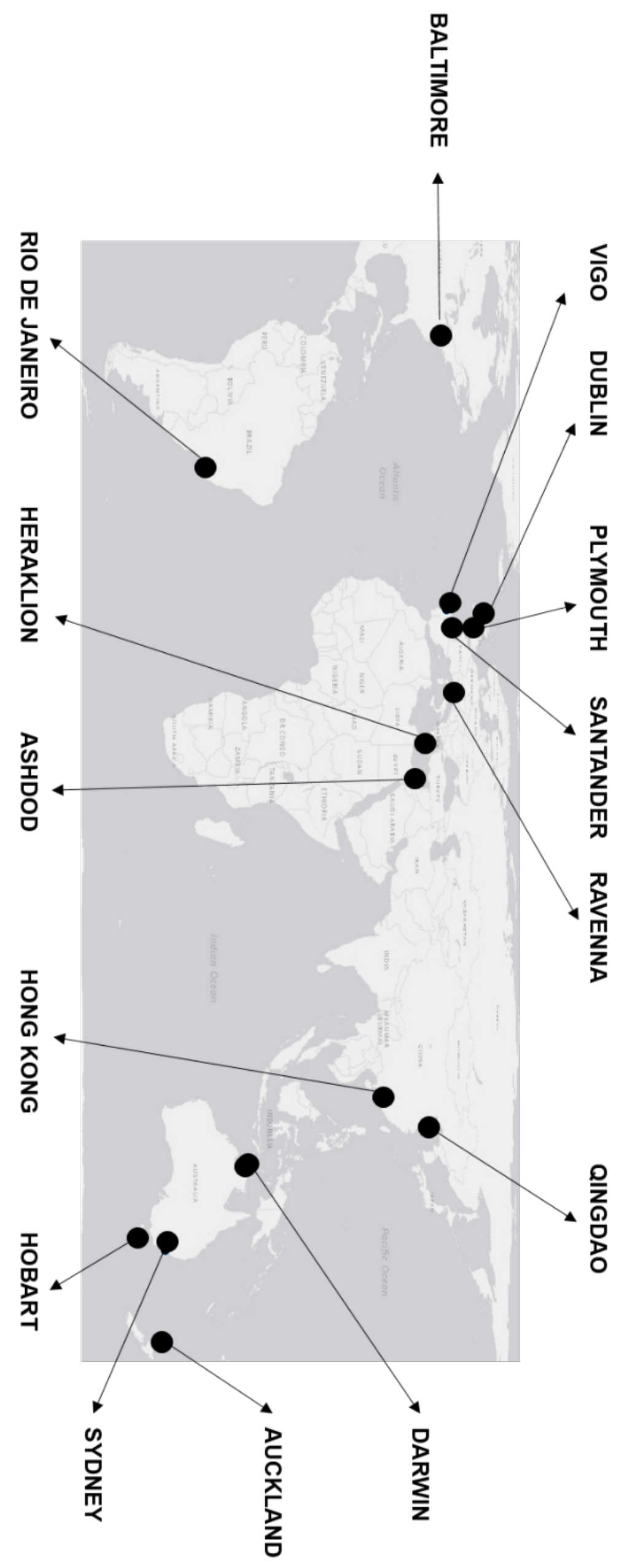




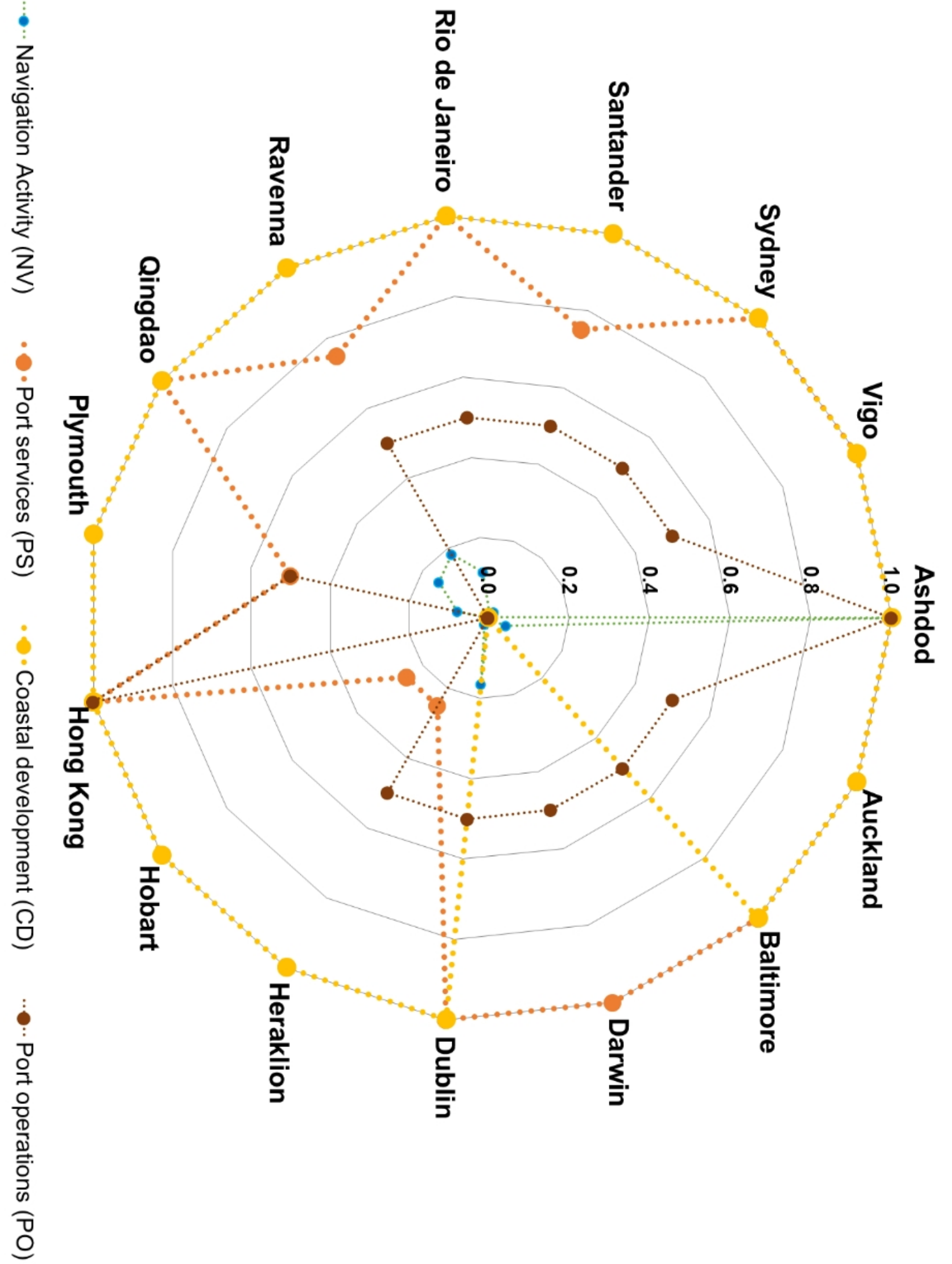




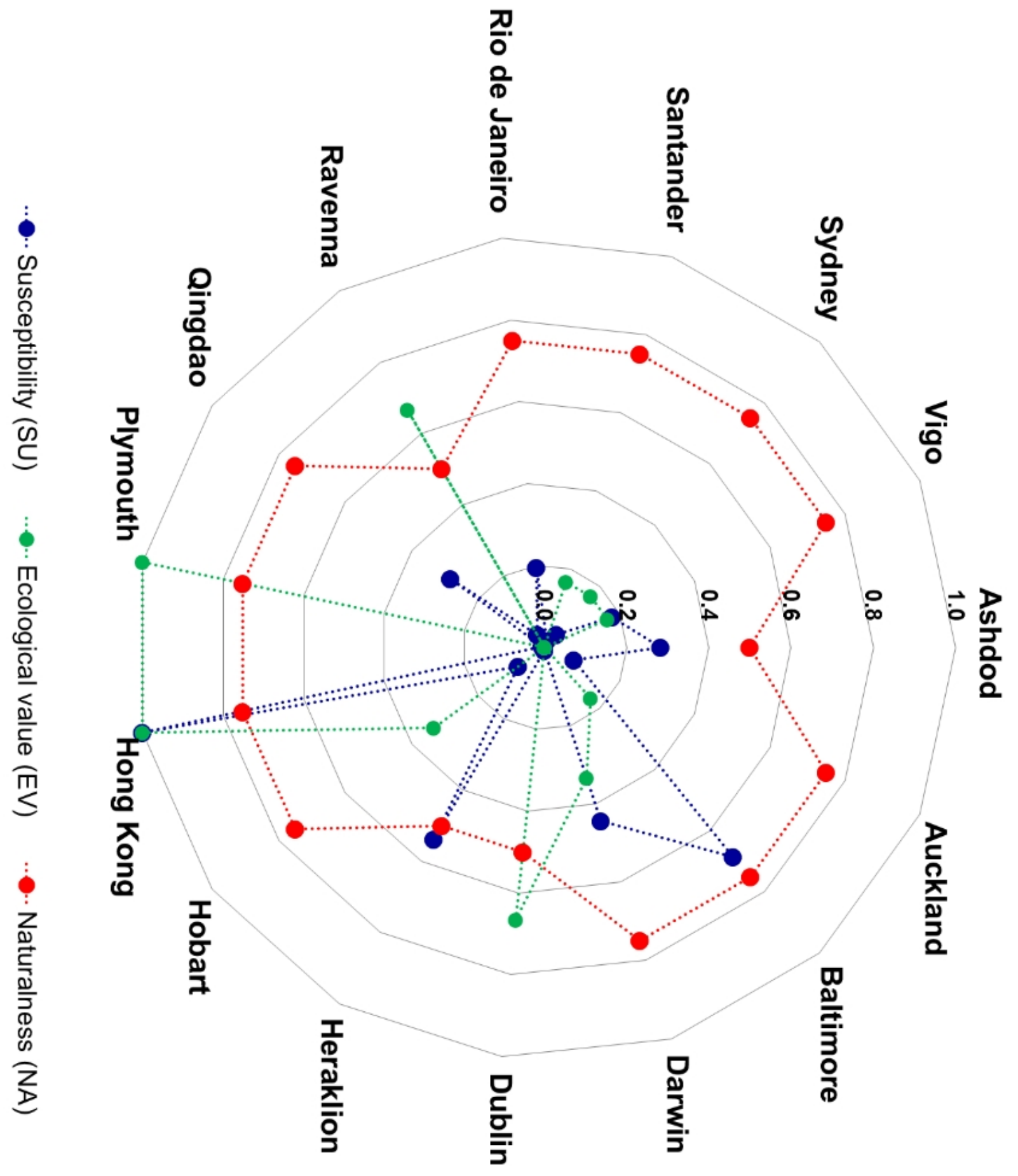




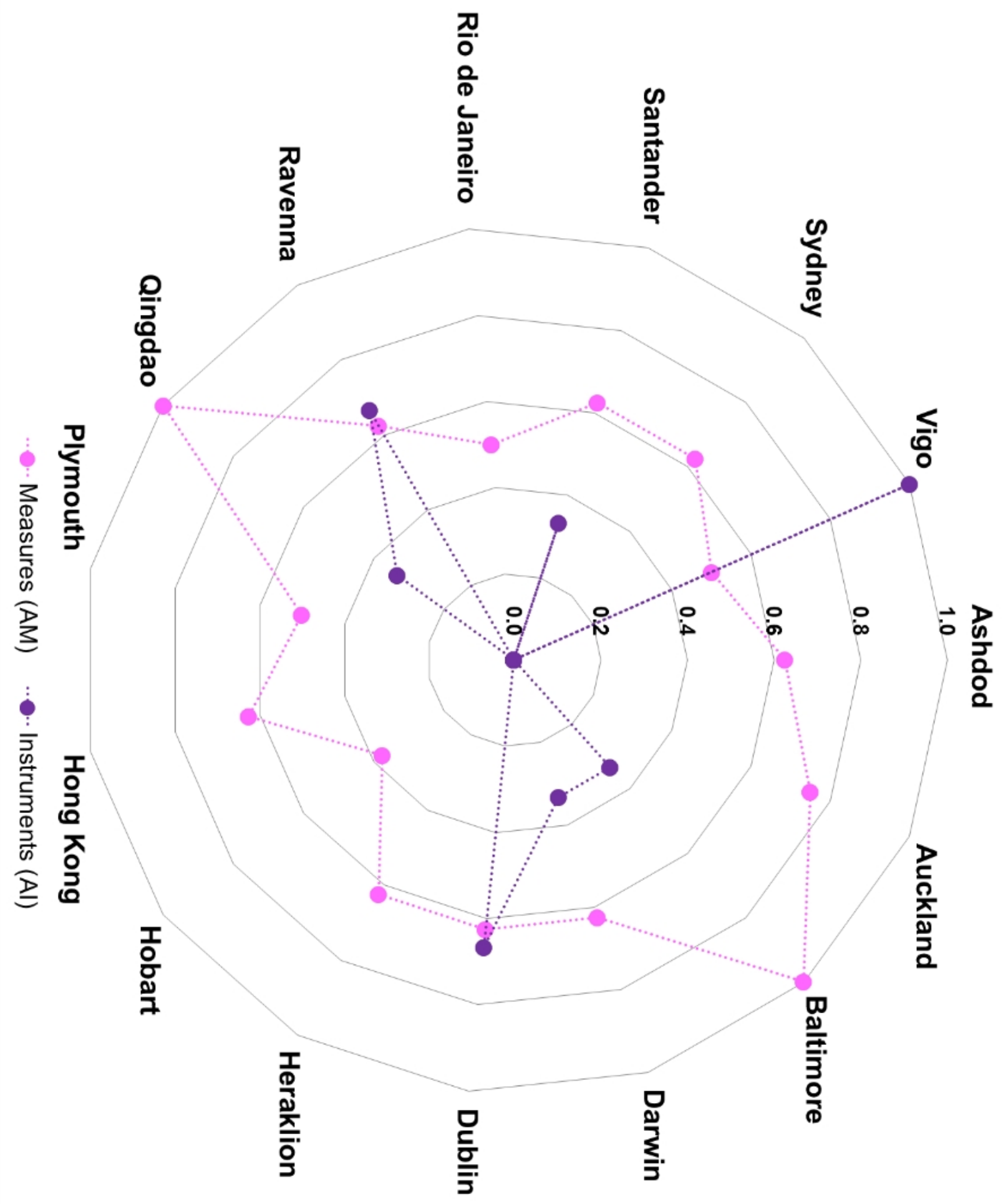




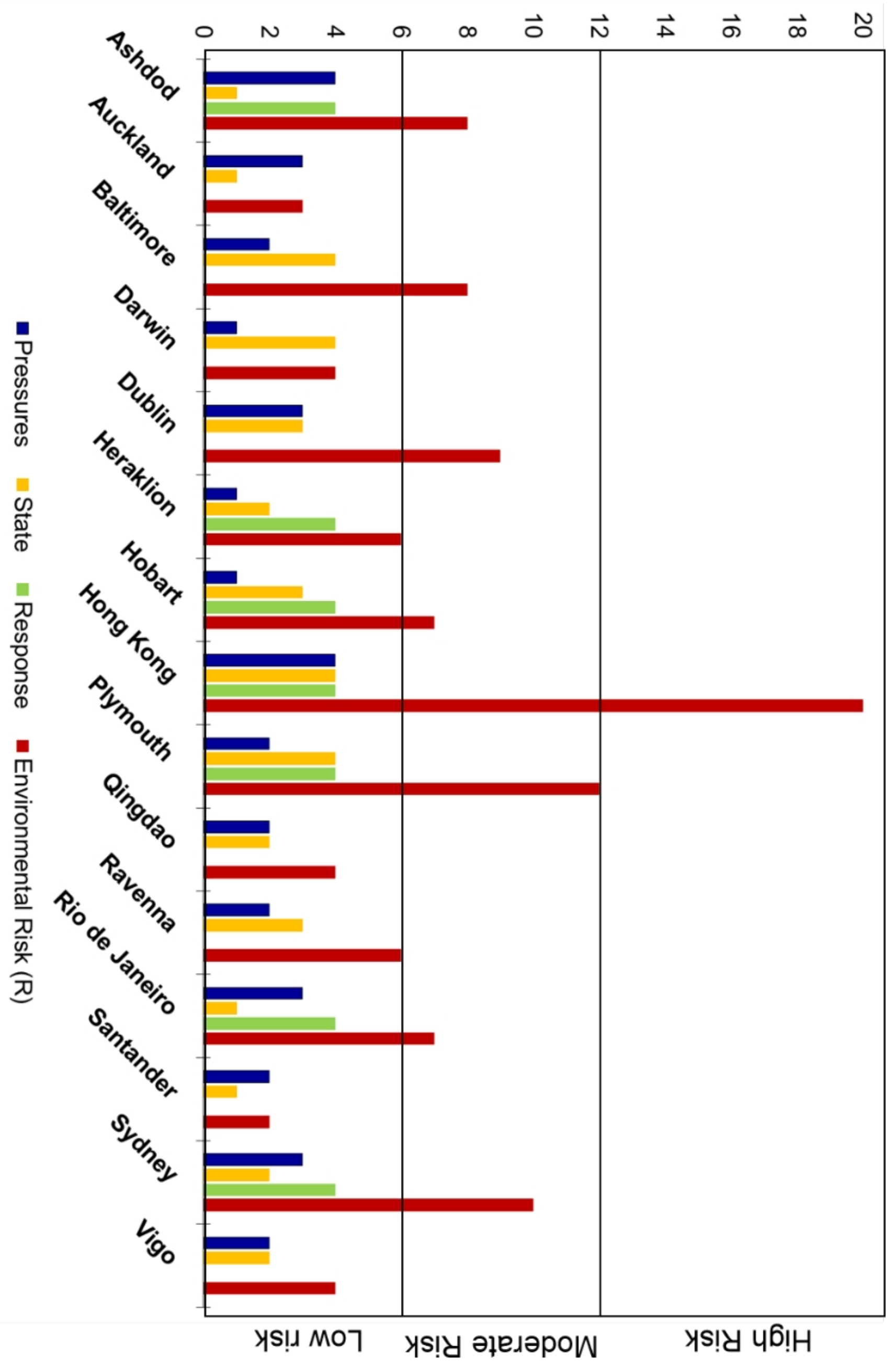



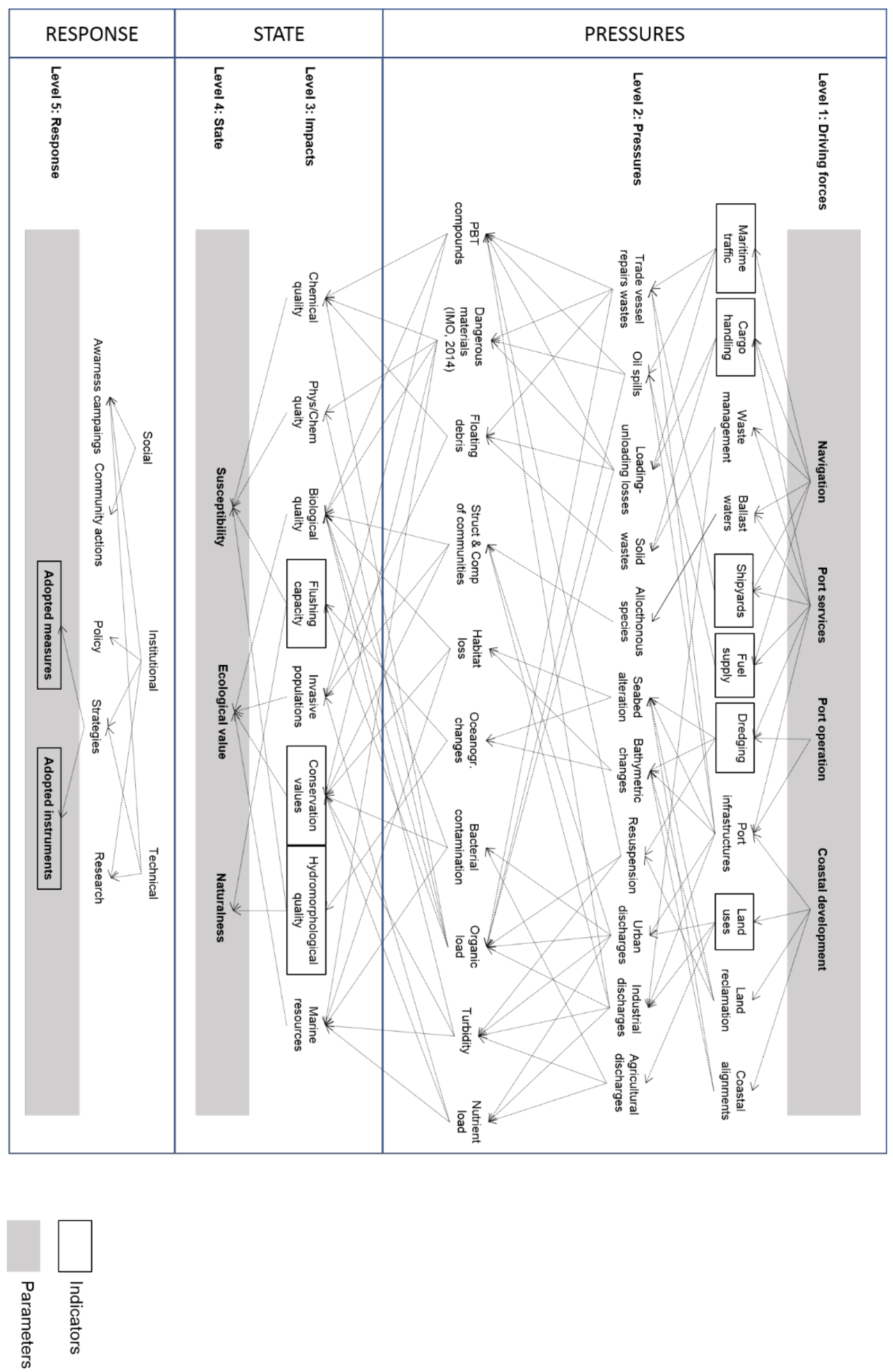


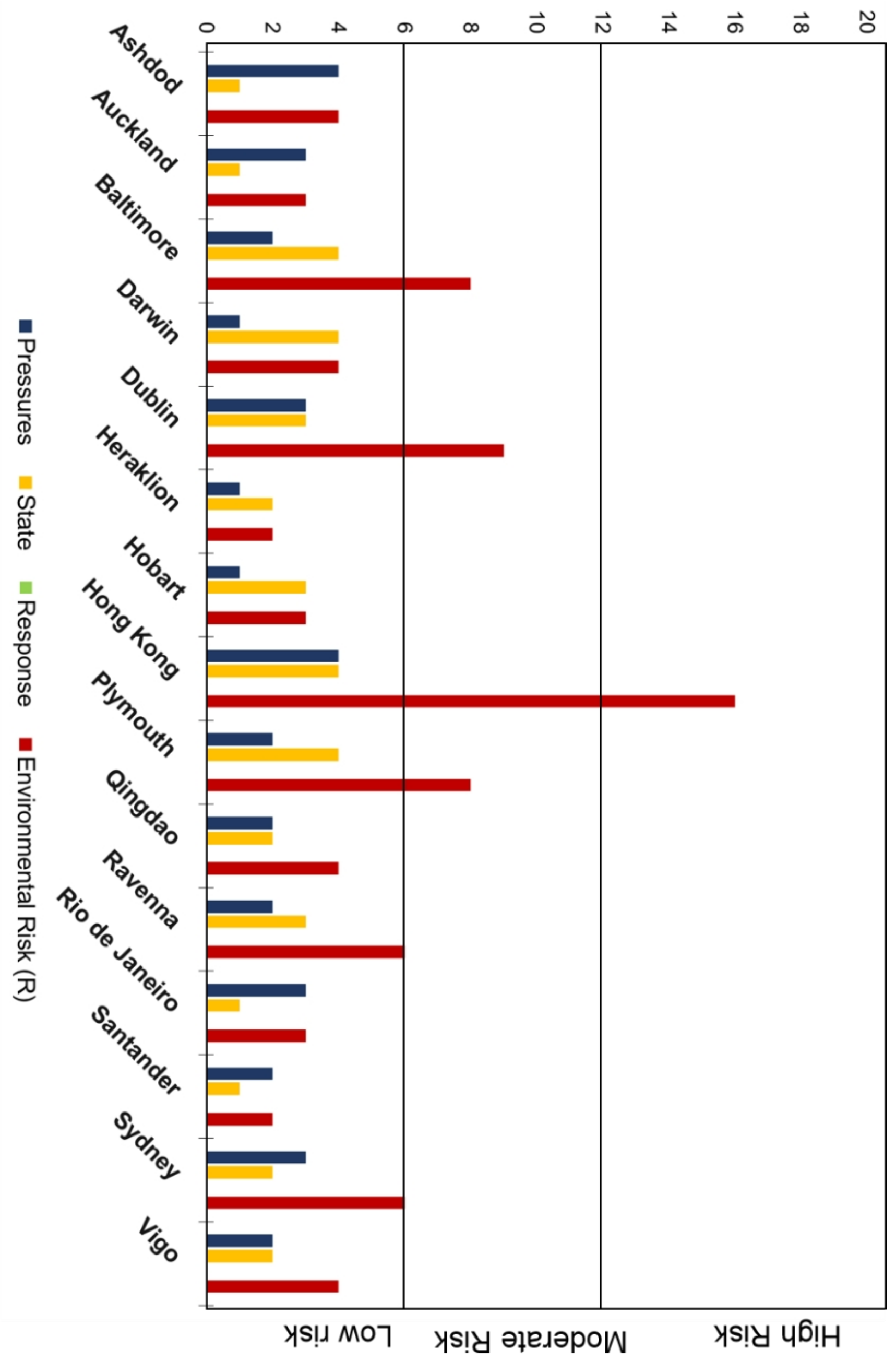




\begin{tabular}{|l|}
\hline General data \\
\hline Harbour's name: \\
Postal address: \\
Code: \\
City: \\
Country: \\
web: \\
phone: \\
e-mail address: \\
\hline Hydromorphological characteristics: \\
\hline Entrance length (in meters): \\
Average tidal range (in meters): \\
Average depth (in meters): \\
Depth at harbour entrance (in meters): \\
\hline Human pressures \\
\hline Number of trade vessels visits per year: \\
Select which activities are developed in the harbour: \\
$\square$ Fuel oil and diesel oil supplies \\
$\square$ Major repair services \\
$\square$ Dangerous/hazardous goods handling \\
Frequency of dredging operations: \\
$\square$ Continual \\
$\square$ Periodic \\
$\square$ No dredging \\
\hline Environmental management \\
\hline Number of Environmental Standard: \\
Please, specify what kind of environmental standards (international certifications) are \\
implemented in the marina: \\
Select which environmental measures are implemented in the harbour: \\
Measures: \\
$\square$ Garbage disposal \\
$\square$ Dirty ballast management \\
$\square$ Bilge management, Sewer Pump-Out \\
Specify any other environmental measure or instrument implemented in the harbour: \\
\hline
\end{tabular}

\section{Application scope}

1. Access to GoogleEarth: https://www.google.es/intl/es/earth/

2. Introduce the name of the harbour in the seeker.

3. Using Add -> Add a polygon: draw the water surface where port activity takes place.

4. Save the polygon as a. $\mathrm{kmz}$ and send it with this questionnaire filled out to: xxxxx.xxxx@unican.es 


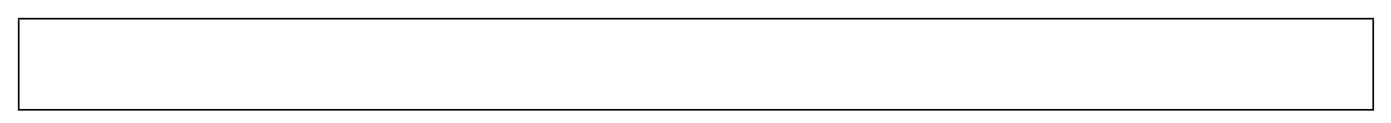


Paloma F. Valdor: Conceptualization, Methodology, Data curation, Resources, Formal analysis, Visualization, Writing - Original Draft, Writing - Review \& Editing Aina G. Gómez: Conceptualization, Methodology, Supervision, Writing - Original Draft, Writing - Review \& Editing Peter Steinberg: Funding acquisition, Writing Review \& Editing Edwina Tanner: Resources, Data curation, Writing - Review \& Editing Antony M. Knights: Resources, Data curation, Writing - Review \& Editing Rochelle D. Seitz: Resources, Data curation, Writing - Review \& Editing Laura Airoldi: Resources, Data curation, Writing - Review \& Editing Louise B. Firth: Resources, Data curation, Writing - Review \& Editing Christos Arvanitidis: Resources, Data curation, Writing - Review \& Editing Massimo Ponti: Resources, Data curation, Writing - Review \& Editing Eva Chatzinikolaouf: Resources, Data curation, Writing - Review \& Editing Paul R. Brooks: Resources, Writing - Review \& Editing Tasman P. Crowe: Resources, Data curation, Writing - Review \& Editing Alison Smith: Resources, Data curation, Writing - Review \& Editing Gonzalo Méndez: Resources, Data curation, Writing - Review \& Editing Aida Ovejero: Resources, Data curation, Writing - Review \& Editing Abilio Soares-Gomes: Resources, Data curation, Writing - Review \& Editing John A. Burt: Resources, Data curation, Writing - Review \& Editing Catriona MacLeod: Resources, Data curation, Writing - Review \& Editing José A. Juanes: Corresponding author, Conceptualization, Methodology, Funding acquisition, Supervision, Project administration, Writing - Review \& Editing 